Pacific Journal of Mathematics

AN EFFECTLESS CUTTING OF A VIBRATING MEMBRANE 


\title{
AN EFFECTLESS CUTTING OF A VIBRATING MEMBRANE
}

\author{
H. F. WEINBERGER
}

Let $G$ be a multiply connected domain bounded by an outer boundary $\Gamma_{0}$, inner boundaries $\Gamma_{1}, \Gamma_{2}, \cdots$, and possibly some other inner boundaries $\gamma_{1}, \gamma_{2}, \cdots$. Let $u$ be the eigenfunction corresponding to the lowest eigenvalue $\lambda_{1}$ of the membrane problem

$$
\Delta u+\lambda_{1} u=0 \text { in } G
$$

with

$$
\begin{aligned}
u=0 & \text { on } \Gamma_{0}, \Gamma_{1}, \cdots \\
\frac{\partial u}{\partial n}=0 & \text { on } \gamma_{1}, \gamma_{2}, \cdots .
\end{aligned}
$$

We shall show that there exists a cut $\tilde{\gamma}$ consisting of a finite set of analytic arcs along which $(\partial u / \partial n)=0$ which separates any given one of the fixed holes, say $\Gamma_{1}$, from the outer boundary $\Gamma_{0}$ and the other holes $\Gamma_{2}, \Gamma_{3}, \cdots$. This means that the membrane $G$ may be cut in two along $\tilde{\gamma}$ without lowering its lowest eigenvalue. This fact is used in the preceding paper of J. Hersch to'establish an upper bound for $\lambda_{1}$.

We assume that $\Gamma_{0}, \Gamma_{1}, \cdots$ have continuous normals and that $\gamma_{1}, \gamma_{2}, \cdots$ are analytic. Then it is well-known that $u$ has the following properties:

(a) $u>0$ in $G$, and $\frac{\partial u}{\partial n}<0$ on $\Gamma_{0}, \Gamma_{1}, \cdots$.

(b) $u$ is analytic in $G+\gamma_{1}+\gamma_{2}+\cdots$.

(c) $u_{x x}$ and $u_{y y}$ do not vanish simultaneously.

(The last property follows from (3a) and (1)).

We define $G_{1}$ to be the set of points of $G$ from which the fall lines, i.e. the trajectories of

$$
\begin{aligned}
& \frac{d x}{d t}=-u_{x} \\
& \frac{d y}{d t}=-u_{y}
\end{aligned}
$$

reach $\Gamma_{1}$. By property (3a) $G_{1}$ contains a neighborhood in $G$ of $\Gamma_{1}$, and its exterior contains neighborhoods in $G$ of $\Gamma_{0}, \Gamma_{2}, \ldots$. Since $u_{x}$

Received August 23, 1962. Prepared under Contract Nonr 710 (16) between the Office of Naval Research and the University of Minnesota. 
and $u_{y}$ are continuous, $G_{1}$ is open.

Let $\tilde{\gamma}$ be the part of the boundary of $G_{1}$ that lies in $G$. Let $P$ be a point of $\tilde{\gamma}$ where the gradient of $u$ does not vanish. Then there is a trajectory $\gamma$ satisfying (4) through $P$. Let $Q$ be any other point on $\gamma$. Since $P$ is not in $G_{1}$, it follows from the definition that $Q$ is not in $G_{1}$. On the other hand, if a whole neighborhood of $Q$ were not in $G_{1}$, it would follow from the continuity of the trajectories with respect to their initial points that a whole neighborhood of $P$ would be outside $G_{1}$. This would contradict the fact that $P$ is a boundary point of $G_{1}$.

Thus we have shown that the whole trajectory $\gamma$ lies in $\tilde{\gamma}_{\text {. It }}$ cannot go to $\Gamma_{1}$. Since the set of points from which trajectories go to $\Gamma_{0}, \Gamma_{2}, \cdots$ is also open, $\gamma$ cannot go to these boundary components.

We note that $u$ is monotone on $\gamma$, and

$$
\left|\frac{d u}{d s}\right|=|\operatorname{grad} u| \text {. }
$$

Thus $\gamma$ is either of finite length, or it must contain a sequence of points $Q_{1}, Q_{2}, \cdots$ on which grad $u$ approaches zero. These will have a limit point $Q$ at which $\operatorname{grad} u=0$. (It may be that $Q$ lies on one of the $\gamma_{i}$. In this case we think of $u$ extended across $\gamma_{i}$ as an analytic function by reflection).

There is a neighborhood of $Q$ in which the trajectories can be determined by examining the first few terms of the power series for $u$. Using property (3c), we find that $\gamma$ is of finite length. This is, of course, true in both the $t$ and $-t$ directions.

The free boundary curves $\gamma_{i}$ are composed of trajectories of (4) and critical points, i.e., points where $\operatorname{grad} u=0$. Hence it follows from the uniqueness of the initial value problem for (4) that if $\gamma$ ends on $\gamma_{i}$, the end point must again be a critical point. Thus, each trajectory $\gamma$ in $\tilde{\gamma}$ connects two critical points.

It follows from properties (3b) and (3c) and the implicit function theorem that a critical point $Q$ is either an isolated critical point or lies on an analytic arc of critical points. These arcs are again isolated.

Thus we have shown that $\tilde{\gamma}$ is composed of a finite number of analytic arcs of finite length along which $(\partial u / \partial n)=0$, and a finite number of critical points. We delete any isolated points of $\tilde{\gamma}$.

The fact that $\tilde{\gamma}$ separates $\Gamma_{1}$ from $\Gamma_{0}, \Gamma_{2}, \cdots$ is clear from the definition of $G_{1}$.

The above considerations apply to any function with properties (3).

The author wishes to thank J. Hersch and D. Ludwig for helpful discussions of this problem. 


\section{PACIFIC JOURNAL OF MATHEMATICS}

\section{EDITORS}

RalPh S. Phillips

Stanford University

Stanford, California

M. G. Arsove

University of Washington

Seattle 5 , Washington
J. Dugundu

University of Southern California

Los Angeles 7, California

Lowell J. Paige

University of California

Los Angeles 24, California

\section{ASSOCIATE EDITORS}
E. F. BECKENBACH
D. DERRY
H. L. ROYDEN
E. G. STRAUS
T. M. CHERRY
M. OHTSUKA
E. SPANIER
F. WOLF

\section{SUPPORTING INSTITUTIONS}

\author{
UNIVERSITY OF BRITISH COLUMBIA \\ CALIFORNIA INSTITUTE OF TECHNOLOGY \\ UNIVERSITY OF CALIFORNIA \\ MONTANA STATE UNIVERSITY \\ UNIVERSITY OF NEVADA \\ NEW MEXICO STATE UNIVERSITY \\ OREGON STATE UNIVERSITY \\ UNIVERSITY OF OREGON \\ OSAKA UNIVERSITY \\ UNIVERSITY OF SOUTHERN CALIFORNIA
}

\author{
STANFORD UNIVERSITY \\ UNIVERSITY OF TOKYO \\ UNIVERSITY OF UTAH \\ WASHINGTON STATE UNIVERSITY \\ UNIVERSITY OF WASHINGTON \\ AMERICAN MATHEMATICAL SOCIETY \\ CALIFORNIA RESEARCH CORPORATION \\ SPACE TECHNOLOGY LABORATORIES \\ NAVAL ORDNANCE TEST STATION
}

Mathematical papers intended for publication in the Pacific Journal of Mathematrcs should be typewritten (double spaced), and the author should keep a complete copy. Manuscripts may be sent to any one of the four editors. All other communications to the editors should be addressed to the managing editor, L. J. Paige at the University of California, Los Angeles 24, California.

50 reprints per author of each article are furnished free of charge; additional copses may be obtained at cost in multiples of 50 .

The Pacific Journal of Mathematics is published quarterly, in March, June, September, and December. Effective with Volume 13 the price per volume (4 numbers) is $\$ 18.00$; single issues, $\$ 5.00$. Special price for current issues to individual faculty members of supporting institutions and to individual members of the American Mathematical Society: $\$ 8.00$ per volume; single issues $\$ 2.50$. Back numbers are available.

Subscriptions, orders for back numbers, and changes of address should be sent to Pacific Journal of Mathematics, 103 Highland Boulevard, Berkeley 8, California.

Printed at Kokusai Bunken Insatsusha (International Academic Printing Co., Ltd.), No. 6 , 2-chome, Fujimi-cho, Chiyoda-ku, Tokyo, Japan.

\section{PUBLISHED BY PACIFIC JOURNAL OF MATHEMATICS, A NON-PROFIT CORPORATION}

The Supporting Institutions listed above contribute to the cost of publication of this Journal, but they are not owners or publishers and have no responsibility for its content or policies. 


\section{Pacific Journal of Mathematics}

\section{Vol. 13, No. $4 \quad$ June, 1963}

Dallas O. Banks, Bounds for eigenvalues and generalized convexity ........... 1031

Jerrold William Bebernes, A subfunction approach to a boundary value problem for

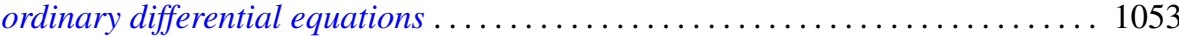

Woodrow Wilson Bledsoe and A. P. Morse, A topological measure construction . . . 1067

George Clements, Entropies of several sets of real valued functions . . . . . . . . . 1085

Sandra Barkdull Cleveland, Homomorphisms of non-commutative *-algebras . . . . . 1097

William John Andrew Culmer and William Ashton Harris, Convergent solutions of

ordinary linear homogeneous difference equations . . . . . . . . . . . . . . . 1111

Ralph DeMarr, Common fixed points for commuting contraction mappings . . . . . . 1139

James Robert Dorroh, Integral equations in normed abelian groups . . . . . . . . 1143

Adriano Mario Garsia, Entropy and singularity of infinite convolutions . . . . . . . 1159

J. J. Gergen, Francis G. Dressel and Wilbur Hallan Purcell, Jr., Convergence of extended Bernstein polynomials in the complex plane ................. 1171

Irving Leonard Glicksberg, A remark on analyticity of function algebras . . . . . . 1181

Charles John August Halberg, Jr., Semigroups of matrices defining linked operators

with different spectra ................................. 1187

Philip Hartman and Nelson Onuchic, On the asymptotic integration of ordinary

differential equations . . . . . . . . . . . . . . . . . . . . . . . . . . . . 1193

Isidore Heller, On a class of equivalent systems of linear inequalities . . . . . . . . . 1209

Joseph Hersch, The method of interior parallels applied to polygonal or multiply

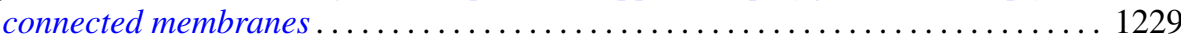

Hans F. Weinberger, An effectless cutting of a vibrating membrane . . . . . . . . . . 1239

Melvin F. Janowitz, Quantifiers and orthomodular lattices ....

Samuel Karlin and Albert Boris J. Novikoff, Generalized convex inequalities . .

Tilla Weinstein, Another conformal structure on immersed surfaces of negative

curvature.

Gregers Louis Krabbe, Spectral permanence of scalar operators

Shige Toshi Kuroda, Finite-dimensional perturbation and a representaion of

scattering operator.

Marvin David Marcus and Afton Herbert Cayford, Equality in certain

inequalities

Joseph Martin, A note on uncountably many disks .

Eugene Kay McLachlan, Extremal elements of the convex cone of semi-norms . . . . 1335

John W. Moon, An extension of Landau's theorem on tournaments . .

Louis Joel Mordell, On the integer solutions of $y(y+1)=x(x$

Kenneth Roy Mount, Some remarks on Fitting's invariants .....

Miroslav Novotný, Über Abbildungen von Mengen ............

Robert Dean Ryan, Conjugate functions in Orlicz spaces.

John Vincent Ryff, On the representation of doubly stochastic operators . . . . . . . . 1379

Donald Ray Sherbert, Banach algebras of Lipschitz functions .

James McLean Sloss, Reflection of biharmonic functions across analytic boundary

conditions with examples.

L. Bruce Treybig, Concerning homogeneity in totally ordered, connected topological space....

John Wermer, The space of real parts of a function algebra...

James Juei-Chin Yeh, Orthogonal developments of functionals and related theorems

in the Wiener space of functions of two variables......... 